\title{
MOVIMIENTOS MIGRATORIOS \\ $Y$ DERECHOS HUMANOS DE LOS \\ EXTRANJEROS: ENTRE EL IMPULSO \\ DE LA SUPERVIVENCIA Y LA DIGNIDAD \\ DE LA PERSONA
}

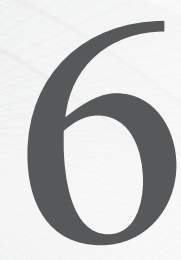

María Méndez Rocasolano

Doutora en Derecho Constitucional por la Full Bright (Harvard). Especialista en Derechos Humanos por la UCAM - España.

Autora convidada

ÁreA do Direito: Internacional; Constitucional

Resumen: Reflexión sobre la naturaleza de las migraciones bajo la premisa de ser un impulso natural y una motivación de mejora en la vida de las personas. Se examinan los flujos migratorios del siglo XXI, estudiando sus causas y efectos en los paises de recepción proponiéndose la adopción de un modelo de Derechos humanos en el que los paises del primer mundo utilicen la razón y la coherencia para aceptar a los inmigrantes dentro de los parámetros de la solidaridad, respeto por la igualdad y la libertad junto con la exportación del respeto de la dignidad de la persona a aquellos paises de procedencia azotados por la barbarie la tiranía y la violación de los Derechos Humanos. Respecto a la libertad de circulación, se revisa suregulación internacional y regional proponiéndose la ampliación de su contenido desde el marco de los Derechos Humanos y la dignidad de la humanidad.

Palabras clave: Derechos humanos - Extranjero - Movimientos migratorios - Dignidad de la persona - Libertad de circulación - Asilo Globalización.

\begin{abstract}
AвSTRACT: This paper rethinks the nature of the migrations under the principle of being a natural impulse and a motivation of improvement in the life of the people. The migratory flows of the $21^{\text {st }}$ century are examined by the perspective of the reception countries, studying its causes and effects of the migration and proposing a model of Human rights in which the countries of the first world use the reason and the coherence to accept to the immigrants within the parameters of solidarity, equality and the freedom when people come from countries whipped by the barbarism, the tyranny and the violation of the Human rights. With respect to the free movement, international and regional subregulation, this paper proposes the extension of its content from the frame of the Human rights and the dignity of the humanity.
\end{abstract}

KEYWORDS: Human rights - Foreign - Migration movements - Human dignity - Free movement - Asylum - Globalization. 
Sumario: 1. Movimientos migratorios a la luz de la naturaleza y la dignidad de la persona - 2. Propuestas desde la coherencia y la razón para los movimientos migratorios del siglo XXI -

3. La libertad de movimientos en nuestro planeta - 4. Referencias bibliográficas.

\section{Movimientos migratorios a la lUZ de la natURAleza y LA DIGNIDAD DE LA PERSONA}

Tradicionalmente desde el Derecho se reflexiona sobre la conducta humana aplicando métodos de las ciencias del espíritu, estudiando lo singular históricamente acotado, los hechos que se dirigen a lo que es intuible y cuyo conocimiento es singular. Frente a ellas, la ciencias de la naturaleza descubren las leyes a las que están sujetos los hechos; se dice que son nomotéticas. ${ }^{1}$ En el caso de las migraciones humanas de las que surgen los conceptos de emigrante, inmigrante y extranjero, así como el plexo de las situaciones en las que estos se encuentran, olvida el Derecho, en muchas ocasiones, que detrás del hombre civilizado está el mamífero de orden Hominidae, género Homo y especie Sapiens ${ }^{2}$ y que desde la revolución neolítica la historia de la Humanidad está acompañada por el desplazamiento de los seres humanos. ${ }^{3}$

1. En este sentido, a finales del siglo XIX, Windelband (1848-1915), siguiendo a Lotze fundador de la filosofía de los valores, desarrolló una teoría de la historiografía basada en las diferencias entre las ciencias de la naturaleza y las ciencias del espíritu. El autor considera insalvable la distancia entre las ciencias nomotéticas y las ideográficas. Así, afirma que: "La ley y el suceso quedan uno al lado del otro como las últimas magnitudes inconmensurables de nuestra representación del mundo. Este es uno de los puntos límites, en los cuales el pensamiento científico tiene solamente la misión de llevar el problema a la luz de la conciencia, pero no está en condiciones de resolverlo". Windelband, Guillermo. Präludien. 4. ed. 1911, p. 379 apud Abbagnano, Nicolas. Historia de la filosofía tomo III. La filosofía del romanticismo. La filosofía entre los siglos XIX y XX. Trad. J. Estelrich y J. Perez Ballestar. Barcelona: Hora, 1982. p. 465-467.

2. Clasificación zoológica del hombre Reino - Animal Phylum - Charolata. Clase Mamalia. Orden - Hominidae Género - Homo Especie - Sapiens.

3. Una brevísima revisión histórica de las migraciones comienza hace unos 9.000 años con los flujos migratorios procedentes de la revolución neolítica que abandona la vida nómada para hacerse sedentaria. En la época clásica Grecia y Roma impulsan las migraciones con carácter colonial y comercial. Tres procesos migratorios masivos se dan en la Edad Media Europea: las invasiones bárbaras, la expansión del Islam y la formación del Imperio bizantino, este periodo de las grandes migraciones sirvió para que muchos pueblos indoeuropeos se establecieran a ambos lados de los antiguos limes del Imperio romano . Extrordinaria importancia tiene el descubrimiento de América que supuso la migración de millones de personas al nuevo mundo. Respecto a la Edad Moderna, los descubrimientos, los Imperios de ultramar y la colonización de otros continentes 
Esta realidad se impone e impregna el significado de migración que en su sentido etimológico indica un cambio de residencia, el desplazamiento de un lugar a otro, lo que es común en el ciclo vital de todos los grupos zoológicos, los cuales aprovechan esta oportunidad para buscar mejores condiciones devida. Un mejor hábitat en el caso de las especies animales migratorias y un mejor lugar donde vivir y desarrollarse en el caso de las personas. En nuestra migración las variables económicas, sociales y culturales son elementos fundamentales para entender las causas que hacen a los seres humanos buscar nuevos espacios donde vivir.

Las migraciones humanas y las consecuencias jurídicas que determinan el tratamiento del desplazado, el estatuto jurídico del extranjero y las múltiples situaciones en relación con su recepción, exigencias de entrada y permanencia, institutos como el asilo, el refugio, la extradición o la expulsión pueden catalogarse como territorios intermedios entre las ciencias nomotéticas y las ideográficas. Han de entenderse desde la dimensión natural y a la luz de la dignidad de la persona, desde el imperativo de los derechos humanos con un enfoque integral del ser humano. Aquí se abre la puerta a las ciencias de la cultura Rickert ${ }^{4}$ y al Derecho como ciencia cultural Lucas Verdú. ${ }^{5}$ Desde esta perspectiva de un Derecho Justo, expresión de una Cultura basada en valores con un enfoque integrado el conocimiento ,es desde donde nos acercamos a la complejidad de las migraciones humanas. Si tenemos en cuenta que el impulso natural es el que lleva al hombre a buscar un lugar donde vivir mejor, no incluiríamos a la migración en uno de los llamados "problemas del siglo XXI". En mi opinión el problema es considerar a los emigrantes un problema...

\section{Propuestas deSde la cOHERENCIA y la RazÓn PARA lOS MOVIMIENTOS MIGRATORIOS DEL SIGLO XXI}

Se impone en nuestras sociedades civilizadas del primer mundo, desde donde escribo, la coherencia. Si entendemos con normalidad que el caribú, el bisonte

fomentaron la emigración europea. Tendremos que esperar a la Revolución Industrial para presenciar el mayor proceso migratorio de toda la historia que no ha terminado aún, sino que está tomando nuevas formas: el llamado éxodo rural. Consecuencia de lo anterior es la llamada Gran Emigración europea (1800-1950) donde millones pobres procedentes de Europa emigraron con rumbo a América y a Australia.

4. Rickert, H. Ciencia cultural y ciencia natural.Trad .G. Morente. Prefacio J. Ortega y Gasset. Buenos Aires: Espasa Calpe S.A., 1943. p. 25.

5. Al respecto recomendamos la lectural de Lucas Verdú, P. Teoría de la Constitución como ciencia cultural. Madrid: Dykinson, 1998. 
americano y los antílopes africanos cada año viajen centenares de kilómetros en búsqueda de una zona en la que abunde el alimento y que les proporcione refugio, cómo es posible que no se entienda que los hombres recorran miles de kilómetros desde los países del Tercer Mundo, hasta los tranquilos y cómodos territorios del primero. Igualmente si tenemos incorporados los Derechos Humanos en nuestra conciencia socio- cultural, cómo es posible que se no comprenda con claridad que son para todos. Quizás debamos repetir incansablemente que los Derechos Humanos son las facultades, prerrogativas, y libertades fundamentales que tiene una persona por el simple hecho de existir, sin los cuales no se puede vivir como tal. Se expresan como derechos civiles y políticos; derechos económicos, sociales y culturales; y derechos de los pueblos o de solidaridad.

Además de la falta de coherencia, parece que es nuestra naturaleza, el instinto, el que se impone a la razón, cuando el grupo humano rechaza al diferente. Desde la antropología social se explica que el rechazo se manifiesta cuando el grupo de acogida siente la amenaza de una invasión debido normalmente a que se les perciben numerosos. En este sentido se manifestaba el alto comisionado de la ONU para los Refugiados, el portugués Antonio Guterres, que alertando sobre el aumento del rechazo a inmigrantes en países mediterráneos concretaba el año pasado que "Los problemas deben discutirse de forma racional y no de manera emocional (...). Europa no podría sobrevivir sin la inmigración". ${ }^{6}$

El planteamiento de la inmigración desde la razón parte de concretar el porqué de la emigración, su naturaleza y significado actual. Si frente al intento fallido de explicar el impulso migratorio de los animales con diversas y variadas teorías, se ha llegado a la conclusión de que normalmente se corresponde con la fase reproductiva, por lo que está determinado por la actividad hormonal y glándular. El impulso de la migración humana, que tiene como base también la supervivencia, se eleva a la dimensión espiritual, valorativa, donde la vida que el que emigra quiere vivir, es una vida más digna, en algunos casos simplemente digna, pues su devenir está encuadrado en perímetros indignos.

Este concepto de dignidad humana es el referente que se impone en la cuestión de la migración actual, que dentro del marco de los derechos humanos ha de desarrollarse con normalidad como un movimiento natural y un fenómeno cultural de los hombres en nuestro Planeta. Ciertamente la dimensión de las corrientes migratorias de los primeros años del siglo XXI causadas por las

6. [www.elecuatoriano.com/noticias/? $\mathrm{p}=10464$ ] 
crisis políticas, socioeconómicas y por la guerra están produciendo un notable impacto sobre la etnicidad de las sociedades receptoras lo que está generando sociedades multiculturales multilingües, y pluriétnicas. El planteamiento es positivo por enriquecedor, Giménez Romero considera que debe respetarse, aprovecharse, y celebrar la "diferencia". Coincidimos con el autor cuando comenta que son sumatorios y no restan, es decir que todas las expresiones culturales, étnicas, religiosas, lingüísticas, están llamadas a estar presentes en la comunidad sociopolítica, a desarrollarse sin represión. Surge con fuerza la idea del axioma antropológico de la igualdad de las culturas y propone el derecho a la diferencia como un posible nuevo derecho de cuarta generación. ${ }^{7}$

La migración internacional tal y como se manifiesta en la actualidad, comenzó a partir de los años cincuenta del pasado siglo XX, hoy asistimos a flujos migratorios que se producen en sentido Sur- Norte, mayoritariamente desde los países pobres a los que no llega el desarrollo de la ciencia y la tecnología, el reconocimiento de los Derechos Humanos, la aceptación de la Democracia como el mejor marco de convivencia pacífica, en definitiva, la aceptación de la libertad e igualdad como valores superiores. ${ }^{8}$

La emigración desde estos países debiera haber remitido, si se hubiesen alcanzado las expectativas de desarrollo, sin embargo el aumento de la pobreza, la corrupción y la tiranía, ha generando desde finales del siglo XX su incremento conformando el origen de las migraciones internacionales del siglo XXI. ${ }^{9}$

7. GimÉnEZ, C. Planteamiento multifactorial para la mediación e intervención en contextos multiculturales: una propuesta metodológica de superación del culturalismo. p. 627- 643. In: F. J. García Castaño; C. Muriel López (eds.). La inmigración en España: contextos y alternativas. Actas del III congreso sobre la inmigración en España (ponencias). Granada: Laboratorio de Estudios Interculturales, 2002. vol. II.

8. Se pone de manifiesto en el espacio norteamericano de los EE.UU, con flujos de inmigrantes latinoamericanos, así como en Europa con los inmigrantes surafricanos. Vid Javier Colomo Ugarte. Desarrollo, subdesarrollo y migraciones internacionales a comienzos del siglo XXI. Revista de la Uned: espacio, tiempo y forma. Madrid: Uned, 2003.

9. Entre los factores considerados como causas fundamentales de la emigración se encuentran las diferencias de renta per cápita entre los distintos países, el elevado crecimiento demográfico de los países que produce excedentes en mano de obra, la pobreza, los sistemas totalitarios, las catástrofes y las guerras. Para consultar datos sobre la migración internacional se ha tenido en cuenta que pueden adquirirse desde tres tipos de fuentes: administrativas, estadísticas de fronteras y estudios de hogares. Entre las fuentes administrativas, se encuentran los registros de extranjeros, los datos 
Desde un enfoque global, la cuestión está en por qué, a finales del siglo se quiebran las barreras de contención que hasta hace poco parecían existir en los países del Tercer Mundo. Según Colomo Ugarte las causas objetivas de las migraciones internacionales de finales del siglo XX y principios del XXI obedecen, en primer lugar, a un desequilibrio entre la situación real de la población y a las expectativas de desarrollo económico. Esto se complementa con un desequilibrio a escala mundial entre países desarrollados y países subdesarrollados. A este doble desequilibrio se añaden las causas subjetivas basadas en la desesperanza y en la frustración.

En este panorama los Derechos Humanos cobran protagonismo, maniféstandose como el máximo exponente de la lucha de la humanidad contra el poder. ${ }^{10}$ Su más concreta expresión es la Declaración Universal de Derechos Humanos que entiende a los hombres "libres e iguales en dignidad y derechos". Las violaciones de los Derechos fundamentales por los sistemas sociopolíticos de los países subdesarrollados suponen el desconocimiento y lejanía de dignidad de la persona, operando junto con los factores económicos como causa indudable del impulso migratorio.

Si efectivamente a nivel internacional se entendiesen los Derechos Humanos sin discriminación alguna y fuesen universales, las motivaciones migratorias no serían tan fuertes como las que se adivinan para los próximos años. La ONU para el 2025 realiza una estimación en la que el porcentaje de emigrantes internacionales podría ascender al 2,7. Esta cantidad es preocupante cuando se refiere al volumen de población inmigrante estimado para Europa en el año 2025, que supondrá el 11,87\% del total de la población europea. En América del Norte, este porcentaje podría ascender al $17,66 \%$ de su población total. Estos datos ponen de manifiesto que los países de acogida experimentarán una notable transformación en la estructura sociocultural debido a la integración del flujo demográfico procedente de los países subdesarrollados. Adelantábamos líneas arriba la reacción negativa y de rechazo que produce en el grupo una afluencia elevada de extranjeros.

e información de visados, permisos de salida, de residencia, y de trabajo entre otros. Respecto a las estadísticas fronterizas recogen los que se adquieren en el control de fronteras. En cuanto a los estudios domésticos y de hogares comprenden censos y diversos tipos de encuestas a hogares. Los datos que arrojan estas fuentes exceden los límites del presente artículo.

10. Al respecto recomiendo la consulta de M. Rocasolano, María y Oliveira da Silveira, Vladmir. Direitos humanos, conceitos, significados e funções. São Paulo: Saraiva, 2010. 
Las sociedades del llamado primer mundo hemos de superar el instinto y razonar, ser coherentes y conscientes que hemos sido nosotros los que en el ámbito euroatlántico inventamos el concepto de dignidad de la persona y lo universalizamos. Hemos de estar preparados para recibir al contingente extranjero desde la responsabilidad de creer en el ser humano y su potencialidad, desde el legado revolucionario de la libertad, la igualdad y la fraternidad. Desde la función de proteger los derechos humanos como carácter innato e inherente a los hombres por el hecho de existir. Tendremos que recordar que son universales, que son inalienables e intransferibles por lo que no se puede, sin afectar a su dignidad, renunciar a ellos o negociarlos. Hemos de tener presente que son indivisibles, interdependientes, complementarios y no jerarquizables, es decir están relacionados entre sí, como diría mi maestro Pablo Lucas Verdu ${ }^{11}$ a través de vasos comunicantes, por lo que no se puede hacer ninguna separación ni pensar que unos son más importantes que otros, lo son todos y todos los son de todos los hombres. La negación de algún derecho en particular significa poner en peligro el conjunto de la dignidad de la persona, ningún derecho puede disfrutarse a costa de los demás. No se puede diferenciar entre extranjeros y nacionales. Entre propios y ajenos.

Son acumulativos, imprescriptibles o irreversibles , así siendo la humanidad cambiante, también sus necesidades, por lo que si estamos ante una revolución transnacional que está reestructurando la sociedad a escala planetaria y las migraciones internacionales son parte de este proceso, necesariamente han de surgir nuevas esferas donde la dignidad de la persona se manifieste como elemento configurador del contenido esencial de nuevos Derechos Humanos sobre la base conceptual de la llamada ciudadanía diferenciada. ${ }^{12}$ Estas ideas van tomando fuerza desde la década de los noventa del pasado siglo generando lo que se conoce como políticas del reconocimiento, lo que según el profesor de filosofía Charles Taylor y el profesor de filosofía política canadiense William Kymlicka lleva a reconocer al otro en el centro de los valores y virtudes de una sociedad democrática. ${ }^{13}$

11. Pablo Lucas Verdú, op. cit. Al respecto de las articulaciones constitucionales y la esencia de los derechos fundamentales véanse p. 45-52.

12. Destaca en el desarrollo de esta idea Iris Marión Young en .Justice and the politics of difference. Princeton: Princeton University Press, 1990 y en Polity and group difference: a critique of the ideal of universal citizenship. New York: State University of New York Press, 1995.

13. Taylor, Ch. El multiculturalismo y "la política del reconocimiento". México: Fondo de Cultura Económica, 1993. Las ideas que comentamos se dirigen hacia conceptos 
Respecto a esos Derechos humanos de esos millones de personas que se establecen en otros países, se plantea una transformación de la soberanía de los Estados que debe ceder ante el carácter inviolable y obligatorio de estos derechos. Se impone la obligación concreta de respeto por los Derechos Humanos, han de trascender real y eficazmente de una vez por todas, las fronteras nacionales. Toca a la comunidad internacional, por encima de la política y la economía intervenir cuando considere que un Estado está violentando los Derechos Humanos de su población.

El definitiva, la globalización ha promovido un cambio tecnológico y una expansión económica sin precedentes, pero también ha acrecentado las desigualdades y ha introducido el concepto de un Planeta homogéneo y estandarizado. La mundialización creciente de la economía y el desarrollo tecnológico de los medios de transporte a finales del siglo XX creó las condiciones para un nuevo tipo de proceso migratorio que han alcanzado hoy grandes dimensiones lo que ha hecho de nuestra Tierra, hoy una "aldea global" con una multidiversidad cultural inimaginable en una economía global. ${ }^{14}$ Se ha superado aquel sistema que ordenaba y organizaba las identidades en función de un concepto de ciudadanía vinculado al de nacionalidad, germen del concepto moderno de extranjero. ${ }^{15}$ Hoy, la mayoría de los grandes desplazamientos humanos se hacen en busca de trabajo y oportunidades huyendo de la guerra, de la miseria y del hambre, con la esperanza de una vida mejor.

Desde diversos posicionamientos que transcurren desde movimientos antiglobalización, hasta los más recientes de los "indignados de Madrid" asistimos a una incipiente toma de conciencia por parte de la sociedad civil que parece plantear la necesidad de una unidad en condiciones de respeto por la dignidad de la persona y los Derechos Humanos de todos y reconociendo lo diferente al mismo tiempo.

como los de Kymlicka de ciudadanía multicultural que desarrolla ampliamente en su obra Ciudadanía multicultural. Una teoría liberal de los derechos de las minorías. Madrid: Paidós, 1996.

14. Castells una economía global es una economía en donde todos los procesos trabajan como una unidad en tiempo real a lo largo y ancho del planeta. Esto es, una economía en la que el flujo de capital, el mercado de trabajo, el mercado, el proceso de producción, la organización, la información y la tecnología operan simultáneamente a escala mundial.

15. Para una revisión histórica del concepto de extranjero, ver Álvarez Dorronsoro, I. Diversidad cultural y conflicto nacional. Madrid: Talasa, 1993. 
Las fronteras, que en el pasado, fueron eficaces límites a la inmigración, en nuestros días cuando los medios de comunicación y de transporte nos muestran el planeta como un todo accesible, no son obstáculo para la esperanza y el irrefrenable deseo de millones de personas de mejorar sus expectativas de vida. Se espera un importante presión de inmigrantes en los países desarrollados, si no queremos reproducir comportamientos xenofóbicos e indignos tendremos que considerar los derechos humanos como Derechos fundacionales siguiendo el dictado del artículo primero de la Declaración Universal que centra su origen en el mero nacimiento de los seres humanos "libres e iguales en dignidad y derechos" "dotados como están de razón y conciencia", obligados a "comportarse fraternalmente los unos con los otros" obligados estamos los países receptores de inmigrantes a comportarnos fraternal y solidariamente con nuestros congéneres.

En conclusión debemos tener en cuenta dos tipos de emigración, la que se hace desde la libertad, el pleno disfrute de los Derechos Humanos y el reconocimiento de la dignidad y aquella forzada, a la que nos referimos en este artículo en la que se huye de condiciones perentorias en busca de una vida mejor. Como posibilidad para reducir la inmigración forzada proponemos la intervención pacífica en sus causas y motivaciones, desde un enfoque nuevo de dignidad referida al colectivo humano, la dignidad de la humanidad donde se podría mantener el concepto de ciudadanía universal ligado a la defensa de todos los derechos de todos, más allá de las fronteras. Aquí los movimientos sociales que convencidos del atributo universal de los derechos humanos responden a estos planteamientos y promueven nuevas formas de cohesión, participación, equilibrio político y económico a nivel mundial tienen protagonismo.

\section{LA LIBERTAD DE MOVIMIENTOS EN NUESTRO PLANETA}

En este nuestro Planeta globalizado del siglo XXI en el que resulta fácil viajar, cerca o lejos, incluso pasearnos por otras mundos a través de la ventana de nuestro computador sin salir de nuestra propia estancia, reflexionamos sobre la libertad de movimiento.

De acuerdo a la Declaración Universal de Derechos Humanos todas las personas tienen el derecho al reconocimiento a una dignidad inherente que les es propia y a ciertos derechos inalienables, lo que es expresión de la libertad y la justicia en nuestro mundo.

El Derecho a la libertad de movimiento es una concreción y forma parte de la libertad, así se reconoce en el art. 13 de la Declaración Universal de Derechos Humanos que establece "toda persona tiene el derecho a la libertad de 
movimiento y residencia dentro de las fronteras de cada estado. Toda persona tiene derecho a salir de cualquier país, incluyendo el suyo y regresar a este" igualmente está regulado en el art. 12 del Pacto Internacional de Derechos Civiles y Políticos, el art. 5 de la Declaración de humanos de los individuos que no son nacionales y en el art. 22 de la Convención Americana sobre Derechos Humanos.

Este un derecho de contenido amplio que incluye otros derechos con los que guarda estrecha relación, como el derecho de cualquier persona a desplazarse en búsqueda de protección y no ser obligado a retornar ni a reubicarse, el derecho al asilo. Así, el reconocimiento por parte de los Estados del derecho a la libertad de circulación, representa una vía efectiva para propiciar el cumplimiento del asilo en cuanto garantía de los Derechos Humanos. En este sentido se ha manifestado el Alto Comisionado de las Naciones Unidas para los Refugiados (ACNUR), respecto al Acuerdo de Schengen, al entender que sus políticas restrictivas por las que se exigen múltiples requisitos para quien quiere entrar en el espacio europeo, contribuyen a una desprotección del asilado. Se ha de tener en cuenta que la causa fundamental generadora de refugiados es la violación generalizada de los derechos humanos y la violencia, por ello el limitar la libertad de circulación y el derecho al asilo a través de un largo listado de requisitos no parece cuadrar con la interpretación que en el ámbito del Consejo de Europa tiene la protección del derecho de asilo, regulado en el artículo 18 de la Carta Europea de los Derechos Fundamentales de la Unión, tampoco con la opinión de la Comisión Europea de Derechos Humanos que considera que la remisión de una persona a un país en que pueda temer persecuciones es un trato inhumano, prohibido por el art. 3 del Convenio Europeo de Derechos humanos. ${ }^{16}$

Quizás en Schengen los europeos no prestamos atención suficiente al carácter dinámico del hombre que hace que el derecho de libertad de circulación tenga importantes consecuencias en el desarrollo cotidiano del devenir de un individuo, por lo que su limitación y/o prohibición, su violación en definitiva, puede afectar profundamente a otros derechos humanos básicos vinculados igualmente a la esfera de la libertad.

Esa libertad en muchos casos es la que se precisa para que las personas puedan alejarse de situaciones adversas. Paradójicamente, vivimos en un

16. El Convenio Schengen, sobre la determinación del primer país de asilo y el Convenio sobre fronteras exteriores de la comunidad fija políticas restrictivas hacia refugiados y demandantes de asilo y busca la coordinación entre los Estados miembros en materia de demandas de asilo. 
mundo donde mientras que unos se mueren de hambre, otros por sobrepeso, se liposuccionan la grasa corporal sobrante. La riqueza y el bienestar crecen a pasos agigantados para algunos mientras que para otros la necesidad, la falta de posibilidades, la precariedad y marginación crecen.

El derecho de libertad de circulación está sujeto a los dictados legales de los países que conforman la comunidad internacional, que en uso de su soberanía establecen en cumplimiento de criterios de seguridad, límites dirigidos a prevenir delitos, salvaguardar la seguridad nacional, el orden, la moral o la salud pública. De esta forma se establecen requisitos legales o administrativos para el ejercicio del derecho de salir o entrar en un país, lo que es absolutante lógico y justo. El problema lo encontramos cuando se desnaturaliza el contenido del derecho a la libertad de circulación, debido a que las mencionadas exigencias se convierten en requisitos que superan el rango de lo razonable. El hecho de que a toda persona le asiste el derecho a salir de cualquier país no significa que exista una obligación correlativa de entrada lo que nos hace reflexionar sobre el contenido del derecho a la libertad de circulación.

Qué libertad es de la que pueden disfrutar refugiados ,solicitantes de asilo, inmigrantes, incluso estudiantes si no se tiene asegurada la entrada a un país cuando se cumplen con las exigencias que resultan normales para el desarrollo del devenir de los nacionales que viven en ellos. Aquí falla el tratamiento igual a los individuos, falla la consideración de los seres humanos somos iguales en derechos y dignidad. Quedan fuera de esta consideración las situaciones delictivas y/o de riesgo de seguridad o sanitario.

Si arriba reflexionábamos sobre la igualdad y los derechos humanos en las migraciones del siglo XXI, ahora nos centramos en la Libertad que afecta a importantes derechos como el mencionado líneas arriba derecho de solicitar asilo que asiste a quien soporta la violación de sus derechos en el país de origen o nacionalidad. Igualmente al derecho que tienen las personas de abandonar su país y regresar sin restricciones. El derecho a la educación que supone la estancia extranjera, el derecho a tener una propiedad, a montar un negocio o empresa etc.

Al respecto son conscientes las instituciones internacionales de la necesidad de garantizar este derecho de libertad de circulación y múltiples son los instrumentos de protección y promoción de este derecho. Tras la Declaración Universal de Derechos Humanos la Convención sobre el Estatuto de los Refugiados en 1951 recogió en su art. 26 que todos sus Estados miembros debían permitir a los refugiados vivir dentro de sus fronteras y trasladarse libremente bajo las reglas que son generalmente aplicadas a extranjeros en igual situación. 
Con la intención de imponer la igualdad por encima de las diferencias raciales, la Convención Internacional sobre la Eliminación de todas las Formas de Discriminación Racial establece en su art. 5 que todas las personas tienen el derecho a la libertad de movimiento añadiendo el derecho a vivienda.

En el mismo sentido se manifiesta el art. 12 del Pacto Internacional de Derechos Civiles y Políticos cuyo Comité de Derechos Humanos elaboró una serie de observaciones en las que se completa y arroja luz sobre los contenidos del Pacto en relación con los extranjeros. Así, destaca la Observación General 15 (sesión 27, 1986) en relación con los derechos de los extranjeros a la libertad de circulación que quedan sujetos a la capacidad soberana que un Estado tiene de elegir quien entra en su territorio. Desde una situación proactiva esta recomendación hace un llamamiento a las naciones a permitir la entrada de cualquier persona cuyos derechos fundamentales estén en juego o a cualquier persona que se enfrente a persecución. ${ }^{17}$

Quizás la más importante de estas observaciones es la número 27 (sesión 27, 1999), ${ }^{18}$ que realiza una reflexión profunda sobre la libertad de movimiento, su significado, manifestaciones y restricciones. En ella, el Comité indica que es indispensable para el libre desarrollo de la persona además de expresar que este derecho interactúa con varios derechos del Pacto Internacional de Derechos Civiles y Políticos. El documento establece una lista de restricciones, las cuales bajo circunstancias excepcionales podrán ser potencialmente impuestas sobre la libertad de movimiento. Este "comentario general" analiza detenidamente los extremos contenidos en las secciones del art. 12 del PIDCP realizando una interpretación legal del mismo. Es uno de los documentos más importantes en

17. El documento también reconoce que los extranjeros podrán ser expulsados o mantenidos fuera del país, si representan una amenaza para los demás. En cuanto a la participación en los asuntos públicos y el derecho de voto otra Observación General la número n. 25, indica que toda persona deberá recibir derechos igualitarios al voto y no deberá existir ningún impedimento para este derecho.

18. Observación General n. 27, Comentarios generales adoptados por el Comité de los Derechos Humanos, art. 12, la libertad de circulación, $67 .^{\circ}$ período de sesiones, U.N. Doc. HRI/GEN/1/Rev.7 at 202 (1999). Art. 12 PIDCP 1. Toda persona que se halle legalmente en el territorio de un Estado tendrá derecho a circular libremente por él y a escoger libremente en él su residencia. 2. Toda persona tendrá derecho a salir libremente de cualquier país, incluso del propio. 3. Los derechos antes mencionados no podrán ser objeto de restricciones salvo cuando éstas se hallen previstas en la ley, sean necesarias para proteger la seguridad nacional, el orden público, la salud o la moral públicas o los derechos y libertades de terceros, y sean compatibles con los demás derechos reconocidos en el presente Pacto. 4. Nadie podrá ser arbitrariamente privado del derecho a entrar en su propio país. 
lo que se refiere al examen profundo de la libertad de movimiento y sus límites. Destaca la relación que tiene con otros derechos consagrados en el Pacto, haciendo referencia a lo observado desde la práctica del Comité en el examen de los informes de los Estados Partes y las comunicaciones de los particulares. Respecto a los Estados Partes insiste en que deben incluir en sus informes al Comité las normas legales y las prácticas judiciales y administrativas internas relacionadas con los derechos protegidos por el art. 12, debiendo incluir también la información sobre los recursos disponibles cuando se limitan dichos derechos.

En el ámbito de la Unión Europa destaca la Declaración sobre los derechos humanos de los individuos que no son nacionales del país en que viven en la que se establecen los derechos básicos de los inmigrantes, refugiados y otros que no son nacionales del país donde residen. En su art. 5 se establece que ninguna restricción podrá ser impuesta sobre la libertad de movimiento de los extranjeros. Los no nacionales no podrán ser forzados a abandonar el país o ser prevenidos de moverse y de elegir residencia dentro de las fronteras del país donde actualmente habitan. Este artículo debe interpretarse bajo las consideraciones que comentábamos relativas al Tratado de Schenguen.

En cuanto a los organismos de la asistencia, protección y del servicio la Organización para la Seguridad y la Cooperación en Europa (OSCE) asiste a los Estados participantes a cumplir sus compromisos en las áreas de libertad de movimiento, elección de lugar de residencia, emigración y contactos humanos. La organización fundamentalmente trabaja con países de Europa del Este, con otras organizaciones internacionales y ONGs para aumentar la protección de derechos y asegurar la no discriminación a varias categorías de inmigrantes.

Teniendo en cuenta que las migraciones actuales son en dirección SurNorte no dejamos atrás la Carta Africana sobre Derechos Humanos y de los Pueblos que es el instrumento principal de los Derechos Humanos en dicho continente. En su art. 12 estipula que las personas tendran el derecho de moverse libremente dentro de las fronteras de su Estado si son ciudadanos que se rigen por la ley. Además establece que todo individuo podrá abandonar y/o regresar a su país a menos que la seguridad nacional, la salud pública o la población en general esté amenazada. Reconoce el derecho a buscar asilo en cualquier país y determina que los extranjeros sólo podrán ser expulsados de una nación de acuerdo a la ley. Resulta interesante la reiterada mención al principio de legalidad y la que realiza en cuanto a la prohibición respecto a las expulsiones en masa de grupos completo de personas, protegiendo los derechos de los grupos étnicos, tan vapuleados en el pasado.

Revisado el significado y regulación de la libertad de circulación, debemos conectarla con la indiscutible movilidad y flexibilidad de los factores de 
producción propios de la globalización, las migraciones económicas Sur-Norte, el resquebrajamiento progresivo del Estado de bienestar, la disminución de las prestaciones sociales en los países desarrollados y el rumor que cada vez se escucha con más fuerza sobre el supuesto umbral de tolerancia respecto al número de extranjeros que un país puede soportar. En este contexto, los medios de comunicación, los Estados y la economía de mercado capitalista juegan un factor decisivo para reinterpretar la libertad de circulación y las propuestas de liberalización de las fronteras.

En primer lugar, los medios de comunicación, las nuevas tecnologías y el desarrollo de los medios de transporte han hecho más sencillo dejar atrás, país, familia y raíces hacia un modelo de vida mejor en los países del Norte. Respecto a las políticas de inmigración estatales, es un denominador común la adopción de políticas restrictivas y selectivas de inmigración sobre la base de intereses demográficos y económicos lo que dificulta el ejercicio de la libertad de circulación. Por su parte la economía y el libre mercado facilitan desplazamientos de trabajadores pero la realidad es que lo hacen en condiciones desiguales y empleos marginales o desregulados, principalmente en el sector servicios donde las internas, camareros y limpiadoras trabajan igual que los jornaleros en la agricultura en condiciones que los nacionales no aceptarían.

Las migraciones que no constituyen una novedad en la historia, y que han funcionado como un elemento dinamizador del desarrollo social, cada vez con mayor intensidad se plantean como un "problema". Decíamos arriba que el problema es considerarlas como un problema, esto parece que todavía no lo entienden las grandes potencias. Se preocupan en buscar posibles alternativas para reducir la llamada "presión migratoria" a través de medidas que van desde las ayudas a la cooperación (Unión Europea), hasta la promoción del comercio internacional (EEUU) pasando por las propuestas de las inversiones directas japonesas. Estas medidas parece que no están dado los resultados esperados.

Aquí proponemos el respeto real por Derechos Humanos entendidos como una totalidad sistemática por una parte para integrarlos en flujos migratorios provenientes de los países del Tercer mundo y por otra para servir como luminaria en el sendero que han de recorrer los países del Tercer mundo para superar el hambre y la miseria, los actos de barbarie, la tiranía y la opresión. La historia nos demuestra que a través de ellos se logra alcanzar situaciones socio-políticoeconómicas y culturales que proporciona a los ciudadanos una vida digna. ${ }^{19}$

19. En este sentido es interesante consultar, BALIBAR, E. "Racisme, nacionalisme, état", en les frontières de la démocratie. Paris: La Découverte, 1992. p. 79-95. Von Werlhof, C.; Bennholdt-Thomsen, V. Y.; Faraclas, N. (eds.). There is an alternative. Subsistence 
El primer paso está en creer que la violación de cualquier derecho en particular, afecta a todos los derechos humanos y que cuando se violan los Derechos Humanos, es agraviada la dignidad de la humanidad y de todos y cada uno de los hombres. El desconocimiento y el menosprecio de los Derechos Humanos ha dado lugar a actos de barbarie ultrajante para la historia y conciencia de la humanidad, por lo que si algo ha de hacer el primer mundo, es esforzarse en imponer ahí donde no se respeten, el reconocimiento y la aplicación universal y efectiva de los derechos humanos. Para ello seamos coherentes y no limitemos la libertad, hagamos esfuerzos para conseguir el eficaz desarrollo y ejercicio de este derecho a lo largo y ancho de nuestro Planeta.

El Portón, agosto 2011.

\section{REFERENCIAS BIBLIOGRÁFICAS}

Abbagnano, Nicolas. Historia de la filosofía tomo III. La filosofía del romanticismo. La filosofía entre los siglos XIX y XX. Trad. J. Estelrich y J. Perez Ballestar. Barcelona: Hora S.A., 1982.

Acnur. La situación de los refugiados en el mundo. Un programa humanitario. Barcelona: Icaria, 1997.

Álvarez Dorronsoro, I. Diversidad cultural y conflicto nacional. Madrid: Talasa, 1993.

Balibar, E. "Racisme, nacionalisme, État", en Les frontières de la démocratie. Paris: La Découverte, 1992.

Blanco, C. Las migraciones contemporáneas. Madrid: Alianza, 2002.

Castells, Manuel. Flujos, redes e identidades: una teoría crítica de la sociedad informacional. Congreso Internacional Nuevas Perspectivas Críticas en Educación. Barcelona: Universidad Autónoma, 1994.

Colomo Ugarte, J. Desarrollo, subdesarrollo y migraciones internacionales a comienzos del siglo XXI. Revista de la Uned: espacio, tiempo y forma. Madrid: Uned, 2003.

Fernández Durán, R. Capitalismo global, resistencias sociales y estrategias del poder. Barcelona: Virus, 2001.

Findlay, A. skilled transients: the invisible fenomenon? In: CoHEn. R. (ed.). The canbridge survey of world migration. Cambridge: Cambridge University Press, 1995.

and Worldwide Resistance to Corporate Globalization. London: Zed Books, 2001; y Fernández Durán, R. Capitalismo global, resistencias sociales y estrategias del poder. Barcelona: Virus, 2001. 
García Castaño; Muriel López, C. La inmigración en España: contextos y alternativas. Actas del III congreso sobre la inmigración en España (ponencias). Granada: Laboratorio de Estudios Interculturales, 2002. vol. II.

GimÉNEZ, C. Planteamiento multifactorial para la mediación e intervención en contextos multiculturales: una propuesta metodológica de superación del culturalismo. In: Garcia Castaño, F. J.; Muriel López, C. (eds.). La inmigración en España: contextos y alternativas. Actas del III congreso sobre la inmigración en España (ponencias). Granada: Laboratorio de Estudios Interculturales, 2002. vol. II.

Hefrernan, M., French colonial migration. In: Cohen, R. (ed.). The canbridge survey of world migration. Cambridge: Cambridge University Press, 1995.

Horrmann-Nowotny, H. J. Switzerland: a non-immigration immigration country. In: Cohen, R. (ed.). The cambridge survey of world migration. Cambridge: Cambridge University Press, 1995.

Kymlicka, W. Ciudadanía multicultural. Una teoría liberal de los derechos de las minorías. Madrid: Paidós, 1996.

LÉvi-Strauss, C. Raza y cultura. Madrid: Altaya, 1999.

López Garrido, D. Estado de Bienestar frente al desafío de la inmigración. In: Fernández García, T.; Garcés Ferrer, Jordi (eds.). Crítica y futuro del Estado del Bienestar. Valencia. Tirant lo Blanch. Madrid 1999.

Lucas Verdú, P. Teoría de la Constitución como ciencia cultural. Madrid: Dykinson, 1998.

. Teoría general de las articulaciones constitucionales. Madrid: Dykinson, 1998.

M. Rocasolano, María; Oliveira da Silveira, Vladmir. Direitos humanos, conceitos, significados e funções. São Paulo: Saraiva, 2010.

Provansal, Danielle. Antropología de las migraciones. Algunos apuntes e interrogantes. In: Prat, Joan et al. Ensayos de antropología cultural. Homenaje a C.Esteva-Fabregar. Barcelona: Ariel, 1996.

Rickert, H. Ciencia cultural y ciencia natural. Trad.G. Morente. Prefacio J. Ortega y Gasset. Buenos Aires: Espasa Calpe S.A., 1943.

Rodríguez Regueira, J. L. Multiculturalismo. El reconocimiento de la diferencia como mecanismo de marginación social. Gazeta de Antropología. n. 17. Granada: Universidad de Granada, 2001.

SASSEN-KoOB, K. The mobility of labor and capital: a study in international investment and labor flow. Cambridge: Cambridge University Press, 1989.

Smith, A. La riqueza de las naciones. Madrid: Alianza, 2001. libros I, II e III.

Solana Ruiz, J. L. Inmigración, hostilidades racistas y propuestas de hospitalidad. Gazeta de Antropología. n. 17. Cidade: Universidad de Granada, 2001.

Sopemi. Tendances des migrations internationales. Paris: OCDE, 1999.

Soros, G. La crisis del capitalismo global. Madrid: Debate, 1999. 
STALKER, P. Workers without frontiers. The impact of globalization on international migration. Ginebra: OIT, 2000.

TAYLOR, Ch. El multiculturalismo y "la política del reconocimiento". México: Fondo de Cultura Económica, 1993.

Veltz, P. Mundialización, ciudades y territorios. Barcelona: Ariel, 1999.

Von Werlhof, C.; Bennholdt-Thomsen, V; Faraclas, N. (eds.). There is an alternative. Subsistence and Worldwide Resistance to Corporate Globalization. London: Zed Books, 2000-2001.

Young, I. M. Polity and group difference: a critique of the ideal of universal citizenship. New York: State University of New York Press, 1995. Justice and the politics of difference. Princeton: Princeton University Press, 1990.

Zapata-BARrero, R. Inmigración e innovación política. Migraciones. n. 8, 2000.

\section{Pesouisas do Editorial}

\section{Veja também Doutrina}

- Cidadania e dupla cidadania, emigração de longo período e voto dos italianos no exterior, de Angela Di Stasi - RT 874/45;

- 0 Estado vs. o estrangeiro reflexões sobre a soberania e a liberalização da imigração, à luz do cosmopolitismo, de Marcelo de Lima - RDCl 74/289; e

- Refugiados ambientais: breves notas sobre sua proteção jurídica internacional, de Liliane Graciele Breitwisser - RDA 56/142. 